\title{
Performance Comparison of Oscillator Circuit Topology for MEMS SAW Resonator
}

\author{
Jamilah Karim , Anis Nurashikin Nordin, Rafidah Rosman
}

\begin{abstract}
This paper presents the simulation results and the performance comparison for three different pierce oscillator circuit topologies. The oscillators were based on the CMOS MEMS SAW resonator. The designs were simulated using 0.35um CMOS technology. Design_3 has the best phase noise performance and settling time as compared to the other two topologies namely Design_1 and Design_2. The settling time for Design_3 was 10ns and the phase noise performance was $90.3 \mathrm{dBc} / \mathrm{Hz}$ at $10-\mathrm{kHz}$ offset frequency. Design_2 required $40 \mathrm{~ns}$ to achieve stability where the phase noise performance was $80.1 \mathrm{dBc} / \mathrm{Hz}$ at $10-\mathrm{kHz}$ offset frequency. Meanwhile, Design_1 required 30ns before it could achieve stability and the phase noise performance was $-\mathbf{5 6} .8 \mathrm{dBc} / \mathrm{Hz}$ at $100-\mathbf{k H z}$ offset frequency. Phase noise performance was the most important criteria for oscillator where in most cases, the resonator used in an oscillator must have high $Q$ in order for the oscillator to have good phase noise performance. However, the sustaining amplifier circuit could also be used to improve the phase noise performance of the oscillator.
\end{abstract}

Index Terms-MEMS based Oscillator, MEMS resonator, MEMS SAW resonator, Pierce Oscillator

\section{INTRODUCTION}

Oscillators are crucial building blocks in transceiver and most electronic platforms. Wireless communication circuits rely on oscillators as stable frequency references to facilitate system synchronization, signal modulation and timing [1].Quartz crystal resonators have traditionally been the most popular form of clock generators. Yet quartz crystals cannot be integrated with microelectronics, losing their high Q advantage to lossy bond wires and large form factors. The motivation for integrated frequency references include smaller form-factors, lower cost, greater flexibilities, higher reliability and batch processing. Efforts to replace quartz technology with more 'silicon-friendly' technologies include CMOS oscillators and silicon micro-electro-mechanical-systems (MEMS) oscillators. CMOS oscillators or electrical oscillators

Jamilah Karim Electrical Engineerng Faculty, Universiti Teknologi MARA, 40450 Shah Alam, Selangor.;

Anis Nurashikin Nordin is with the ECE Department, Kulliyyah of Eng., International Islamic University Malaysia, Gombak, Kuala Lumpur

Rafidah Rosman Electrical Engineerng Faculty, Universiti Teknologi MARA, 40450 Shah Alam, Selangor.; rely on LC filters to select their frequencies and are defined by their low-Q CMOS inductors. This ranges from 10-20 [2]. In contrast, MEMS oscillators utilize mechanical vibrations as their frequency selective element and exhibit Qs in the order of millions [3]. Silicon-compatible MEMS resonators can be fabricated on a CMOS [4] or packaged with CMOS circuits in a single package [3]. Silicon-compatible MEMS resonators were preferred due to their reduced size, cost and increased level of system integration.

This work illustrates different oscillator topologies which are suitable for a CMOS MEMS SAW resonator. Basic oscillator topologies are discussed in Section II while Section III explains the oscillator circuit design. The simulation output and discussion is explained in Section IV and Section V concludes the paper.

\section{OSCILLATOR TOPOLOGIES}

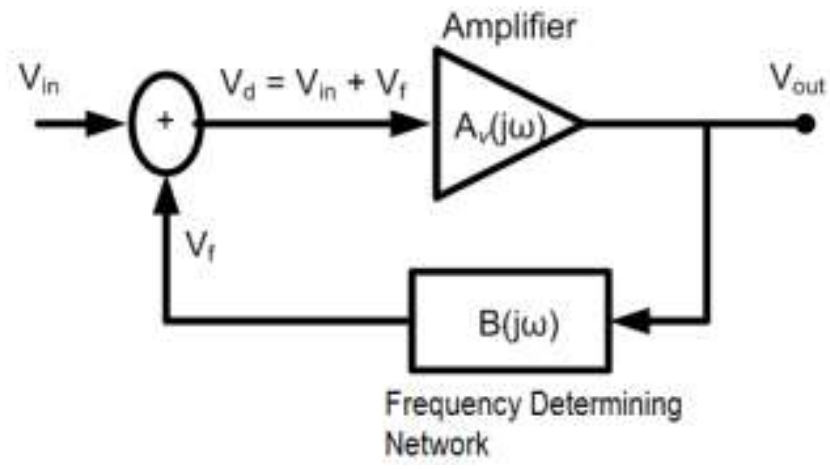

Figure 1: Basic Oscillator System

The basic oscillator system which comprises of an amplifier circuit and its frequency determining network is shown in Figure 1. The frequency determining network can either be the resonator or the RC or LC circuit. In this work, the frequency determining device used was a MEMS SAW resonator.

CMOS MEMS SAW resonator is made from piezoelectric material. This resonator was introduced in [5] . The resonance frequencies of CMOS MEMS SAW resonator ranges from $600 \mathrm{MHz}$ to $3.12 \mathrm{GHz}$ while the Q factor ranges from 33 to 94[5]. The resonators were formed when the two IDTs were placed between the reflectors. Reflectors are key components of the SAW resonator. The reflectors will restrain the outward propagating wave within the cavity and thus reduces the losses. Here, the $\mathrm{IDT}_{1}$ is the transmitter while $\mathrm{IDT}_{2}$ is the receiver. From Figure 2, IDT 1 is connected to $V_{\text {in }}$ and IDT $_{2}$ is short circuit to sense the current $\mathrm{I}_{\text {out }}$. The operating principle of SAW device is based on the piezoelectric effect. When a 
microwave voltage input was applied at the transmitting (input) IDT, it generates a propagating acoustic wave on the surface of the substrate. This propagating acoustic wave in turn produces an electric field localized at the surface which can be detected and translated back into an electrical signal at the output IDT port. Thus, with the existence of reflector, the resonance frequency can be created.

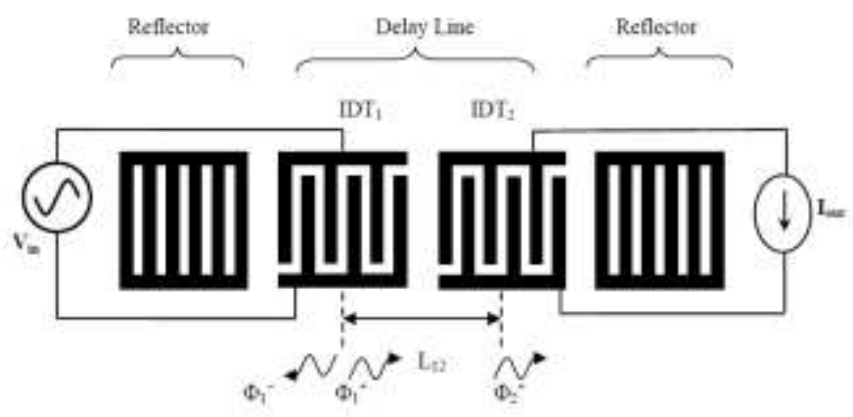

Figure 2: Schematic of two-port SAW resonator

Since MEMS SAW resonators are lossy, they typically require amplifiers to start and sustain oscillation. The sustaining amplifier circuits define the oscillator topology where there are several oscillator topologies namely; pierce oscillator, transimpedance amplifier, differential amplifier, colpitts oscillator, Hartley oscillator and cross coupled oscillator. However, MEMS based oscillator used only differential amplifier circuit[6], pierce circuit[7]-[11] and transimpedance amplifier circuit[12]-[16]. The topology chosen is normally based on the design specifications such as low power and low noise oscillator. Besides that, the $\mathrm{R}_{\mathrm{x}}$ and the insertion losses of the resonator contribute to the suitability of the topology chosen.

Table 1:

DC PERFORMANCE OF THE OSCILLATOR CIRCUIT TOPOLOGIES

\begin{tabular}{|c|c|c|}
\hline Ref. & $\begin{array}{l}\text { Amplifier } \\
\text { Topology }\end{array}$ & DC Performance \\
\hline [7] & Pierce Circuit & $\begin{array}{l}\mathrm{g}_{\mathrm{m}}=10.47 \mathrm{mS} \\
\mathrm{V}_{\mathrm{ds}}=764 \mathrm{mV} \\
\mathrm{I}_{\mathrm{d}}=582.4 \mu \mathrm{A}\end{array}$ \\
\hline [17] & Pierce Circuit & $\begin{array}{l}\mathrm{g}_{\mathrm{m}}=12.6 \mathrm{mS} \\
\mathrm{V}_{\mathrm{ds}}=731 \mathrm{mV} \\
\mathrm{I}_{\mathrm{d}}=554.1 \mu \mathrm{A}\end{array}$ \\
\hline [9] & Pierce Circuit & $\begin{array}{l}\mathrm{g}_{\mathrm{m}}=8.33 \mathrm{mS} \\
\mathrm{V}_{\mathrm{ds}}=736 \mathrm{mV} \\
\mathrm{I}_{\mathrm{d}}=535.8 \mu \mathrm{A}\end{array}$ \\
\hline [10] & Pierce Circuit & $\begin{array}{c}\mathrm{g}_{\mathrm{m}}=2.55 \mathrm{mS} \\
\mathrm{V}_{\mathrm{ds}}=812 \mathrm{mV} \\
\mathrm{I}_{\mathrm{d}}=669 \mu \mathrm{A}\end{array}$ \\
\hline [18] & $\begin{array}{c}\text { Transimpedance } \\
\text { Amplifier } \\
\text { Circuit } \\
\end{array}$ & $\begin{array}{c}\mathrm{g}_{\mathrm{m}}=3.16 \mathrm{mS} \\
\mathrm{V}_{\mathrm{ds}}=1.09 \mathrm{~V} \\
\mathrm{I}_{\mathrm{d}}=535 \mu \mathrm{A}\end{array}$ \\
\hline [19] & $\begin{array}{c}\text { Transimpedance } \\
\text { Amplifier } \\
\text { Circuit }\end{array}$ & $\begin{array}{c}\mathrm{g}_{\mathrm{m}}=2.56 \mathrm{mS} \\
\mathrm{V}_{\mathrm{ds}}=795.2 \mathrm{mV} \\
\mathrm{I}_{\mathrm{d}}=638.8 \mu \mathrm{A}\end{array}$ \\
\hline [16] & $\begin{array}{c}\text { Transimpedance } \\
\text { Amplifier } \\
\text { Circuit } \\
\end{array}$ & $\begin{array}{c}\mathrm{g}_{\mathrm{m}}=2.73 \mathrm{mS} \\
\mathrm{V}_{\mathrm{ds}}=765.2 \mathrm{mV} \\
\mathrm{I}_{\mathrm{d}}=598.8 \mu \mathrm{A}\end{array}$ \\
\hline
\end{tabular}

Among all the topologies mentioned, pierce circuit is the simplest, provide straightforward biasing and easier to design.

Pierce circuit topology and TIA circuit topologies in [7][10], [14]-[16] was simulated using MIMOS $0.35 \mu \mathrm{m}$ technology. Their DC simulation results are summarized in Table 1. Clearly, the result in Table 1 shows that pierce circuit topologies result in very high transconductance, $\mathrm{g}_{\mathrm{m}}$ compared to TIA circuit topologies. The $\mathrm{g}_{\mathrm{m}}$ of Pierce circuit topologies ranges from $2.55 \mathrm{mS}$ to $12.6 \mathrm{mS}$. The topology introduced by [8] yielded the highest $\mathrm{g}_{\mathrm{m}}$ which was $12.6 \mathrm{mS}$ at $\mathrm{V}_{\mathrm{ds}}=731 \mathrm{mV}$ and $\mathrm{I}_{\mathrm{d}}=554.1 \mu \mathrm{A}$. Meanwhile, the Pierce topology introduced in [10] only produced $\mathrm{g}_{\mathrm{m}}=2.55 \mathrm{mS}$. This topology was biased with $\mathrm{V}_{\mathrm{ds}}=812 \mathrm{mV}$ and $\mathrm{I}_{\mathrm{d}}=669 \mu \mathrm{A}$. Both circuits were based on inverter circuit, but the Pierce circuit in [8] has the feedback impedance that provided sufficient impedance to ensure the necessary $g_{m}$ was achieved. The TIA circuit topologies shown in this table produced $\mathrm{g}_{\mathrm{m}}$ from $2.56 \mathrm{mS}$ to $3.16 \mathrm{mS}$. The topologies biased at $\mathrm{V}_{\mathrm{ds}}$ from $765 \mathrm{mV}$ to $1.09 \mathrm{~V}$. The bias current for the lowest $\mathrm{g}_{\mathrm{m}}$ for TIA circuit topology was $638.8 \mu \mathrm{A}$ while the highest $\mathrm{g}_{\mathrm{m}}$ was $535 \mu \mathrm{A}$.

Both topologies did not show much difference in terms of their biasing of $V_{d s}$ and $I_{d}$. However, with slight differences Pierce circuit topology yielded very high $\mathrm{g}_{\mathrm{m}}$. Therefore, Pierce circuit topologies are highly recommended to be used in oscillator circuit design for this work.

\section{PIERCE OSCILlator CIRCUIT DESIGN}

The oscillator generated oscillation without any external input. The sustaining circuit or the amplifier circuit with the ability of self-sustaining allowed its own noise to grow and developed the periodic signal. The performance of the MEMS base oscillator is not only dependent on the resonator but also on the supporting circuit.

To provide the oscillation, the MEMS resonator will normally be embedded in the feedback loop of an amplifier as shown in Figure 1. To achieve oscillation, the Barkhausen criterion was necessary but not sufficient [20]. To ensure oscillation in the presence of temperature and process variation the loop gain has to be chosen at least twice or three times the required value [21]. The criterion is written in equations (3) and (4) below. $\left|\boldsymbol{\beta}(\boldsymbol{j} \omega) \boldsymbol{A}_{v}(\boldsymbol{j} \boldsymbol{\omega})\right|=\mathbf{1}$

$$
\left|\beta(j \omega) A_{v}(j \omega)\right|=1
$$

And

$$
\angle \beta(j \omega) A_{v}(j \omega)= \pm n 360^{\circ}
$$

where $n=0,1,2,3 \ldots \ldots \ldots \ldots \ldots \ldots \ldots$ 
Pierce oscillator circuit topology was chosen in this work. The choice of the topology was based on the need for low power consumption and low phase noise. This topology was often chosen for its low frequency quartz crystal oscillators (Otis, 2002). Pierce circuit topologies were well known for its frequency stability and can be used for a wide range of frequencies. Besides the circuit simplicity it has, the topology was also ideal for low current and low voltage circuit design (Otis, 2002) as they provided straight forward biasing.

Three Pierce Oscillator circuits topology were used to analyze the performance of CMOS oscillator based on CMOS MEMS SAW resonator, R3_S2. Figure 3 and Figure 4 show the detail schematic diagram of Pierce Oscillator circuit topology integrated with the resonator R3_S2 respectively. In later parts of the discussion, the topology in Figure 3 is called Design_1 while the topology in Figure 4 is called Design_2. The results were then being compared with the performance of Pierce oscillator circuit of Figure 5 known as Design_3. All the three topologies in Figure 3, Figure 4 and Figure 5 showed that the pierce oscillator will amplify the signal from the resonator output and fed the signal back to the resonator. Thus, the oscillation was sustained.

$\mathrm{T}_{1}, \mathrm{~T}_{4}$ and $\mathrm{T}_{7}$, are the single stage pierce circuit topology for Figure 3 and Figure 5, while for Figure 4 where the first stage consist of $T_{1}, T_{4}, T_{5}$ and $T_{9} . T_{1}$ is the main transistor that provides the critical transconductance for oscillation and was biased by transistor $\mathrm{T}_{4}$. Besides providing the bias resistance to the gate of $T_{1}, T_{7}$ and $T_{9}$ also provided enough resistance to ensure that the oscillation could be sustained. The rest of the transistors in the figures were then added to become the second and third stages in order to ensure that the oscillation could be started and sustained.

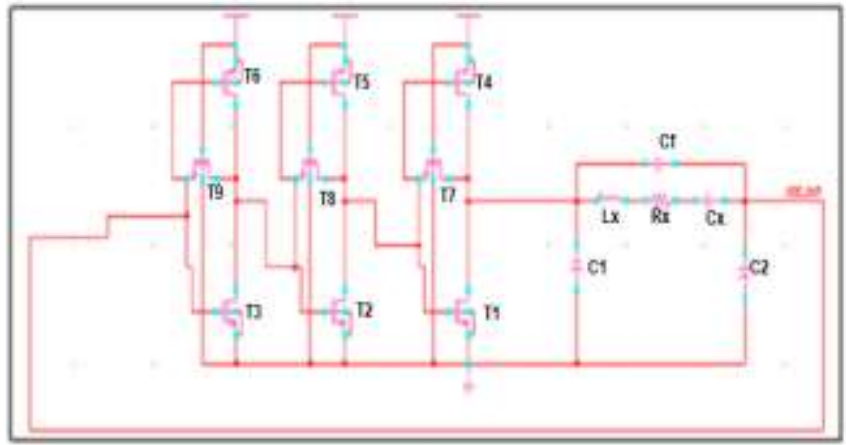

Figure 3: Detail schematic of Pierce Oscillator circuit topology for Design_1

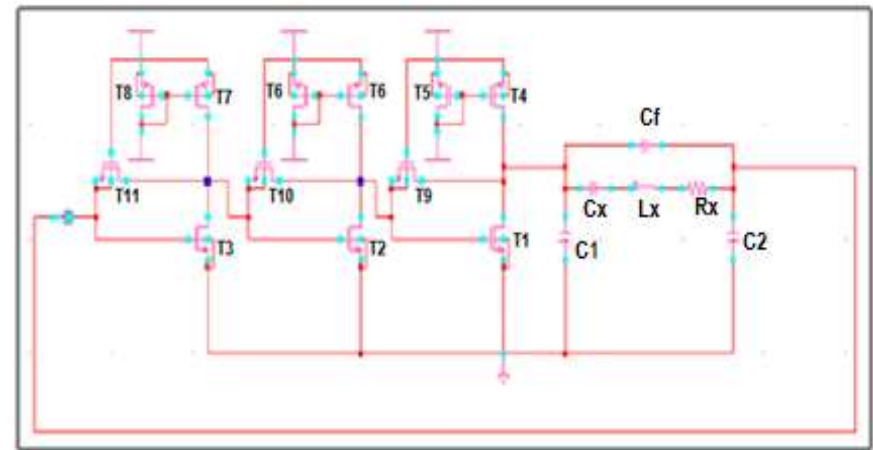

Figure 4: Detail schematic of Pierce Oscillator circuit topology for Design_2

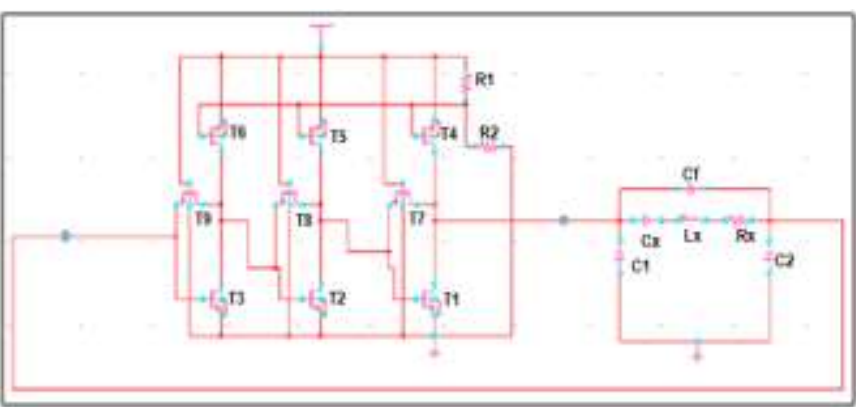

Figure 5: Detail schematic of Pierce Oscillator circuit topology for Design_3

The equivalent circuit parameter of MEMS SAW resonator used in this work is summarized in Table 2.

Table 2:

PARAMETER OF MEMS SAW RESONATOR

\begin{tabular}{|c|c|c|c|c|c|}
\hline \hline Element & $\mathrm{R}_{\mathrm{x}}(\Omega)$ & $\mathrm{L}_{\mathrm{x}}(\mathrm{uH})$ & $\mathrm{C}_{\mathrm{x}}(\mathrm{fF})$ & $\mathrm{C}_{\mathrm{f}}(\mathrm{fF})$ & $\begin{array}{c}\mathrm{C}_{1}=\mathrm{C}_{2} \\
(\mathrm{fF})\end{array}$ \\
\hline R3_S2 & 185 & 1.6 & 5 & 143.8 & 300 \\
\hline \hline
\end{tabular}

Table 3 shows the DC operating parameters for all the 3 oscillator topologies during oscillation. Design_2 was biased at $0.921 \mathrm{~mA}$ while Design_1 and Design_3 was biased at $1.1 \mathrm{~mA}$. The biasing voltage for Design_1, Design_2 and Design_3 were $0.72 \mathrm{~V}, 0.811 \mathrm{~V}$ and $0.750 \mathrm{~V}$ respectively. The power consumed by all the designs when integrated with R3_S2 is $2.38 \mathrm{~mW}$ for Design_1, 2.24mW for Design_2 and $2.47 \mathrm{~mW}$ for Design_3. The highest power consumption is topology in Design_3 and the lowest power consumption is topology in Design_2. It is then clear that the oscillator to be used in wireless systems should consume a minimum amount of power. However, since the SAW resonator used in this work has large values of $C_{1}$ and $C_{2}$, larger bias current was then required. Therefore, larger power was required to sustain the oscillation for this oscillator based on the MEMS SAW resonator. 
Table 3:

DC operating parameters at which the oscillators oscillate

\begin{tabular}{|c|c|c|c|c|c|}
\hline \hline Element & $\mathrm{V}_{\mathrm{dd}}(\mathrm{V})$ & $\mathrm{I}_{\mathrm{d}}(\mathrm{mA})$ & $\mathrm{V}_{\mathrm{ds}}(\mathrm{V})$ & $\begin{array}{c}\mathrm{g}_{\mathrm{m}} \\
(\mathrm{mS})\end{array}$ & $\begin{array}{c}\mathrm{P}_{\text {consume }} \\
(\mathrm{mW})\end{array}$ \\
\hline Design_1 & 3 & 1.100 & 0.720 & 10.6 & 2.38 \\
\hline Design_2 & 3 & 0.921 & 0.811 & 6.6 & 2.24 \\
\hline Design_3 & 3 & 1.100 & 0.750 & 9.6 & 2.47 \\
\hline \hline
\end{tabular}

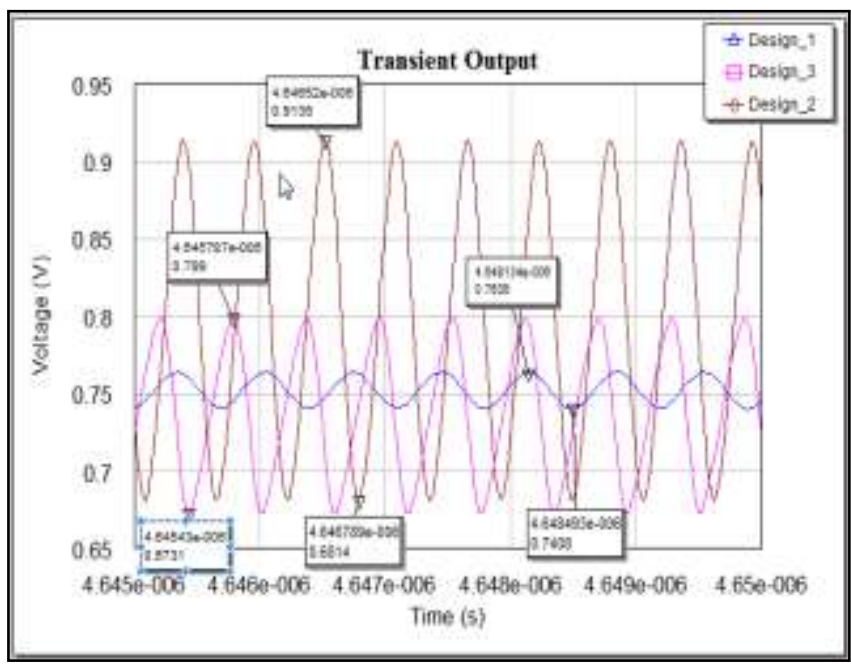

Figure 6: Transient Output for three different topologies simulated with R3_S2

The transient output of all the three Pierce topologies was plotted in Figure 6. Design_2 shows the highest amplitude oscillation which was $232 \mathrm{mV}$ and generating a $1.77 \mathrm{GHz}$ frequency. The amplitude oscillation for Design_3 is $126 \mathrm{mV}$ at $1.75 \mathrm{GHz}$ resonance frequency. While Design_1 yielded very low voltage output among the three which was $23 \mathrm{mV}$ with achievable resonance frequency at $1.5 \mathrm{GHz}$. This was far from the resonance frequency of the MEMS SAW resonator.

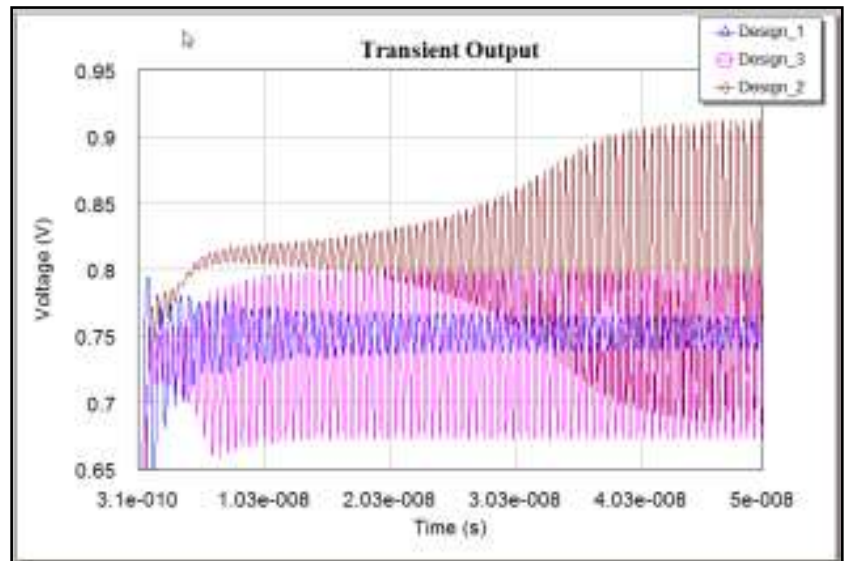

Figure 7: Settling time for three different topologies simulated with R3_S2
Figure 7 shows the settling time for the three topologies when simulated with resonator R3_S2. The figure clearly show that Design_2 required 40ns to achieve stability while Design_1 required 30ns. Apparently, Design_3 has the shortest settling time which was only $10 \mathrm{~ns}$. The settling time will determine how fast the systems respond from one frequency to another.

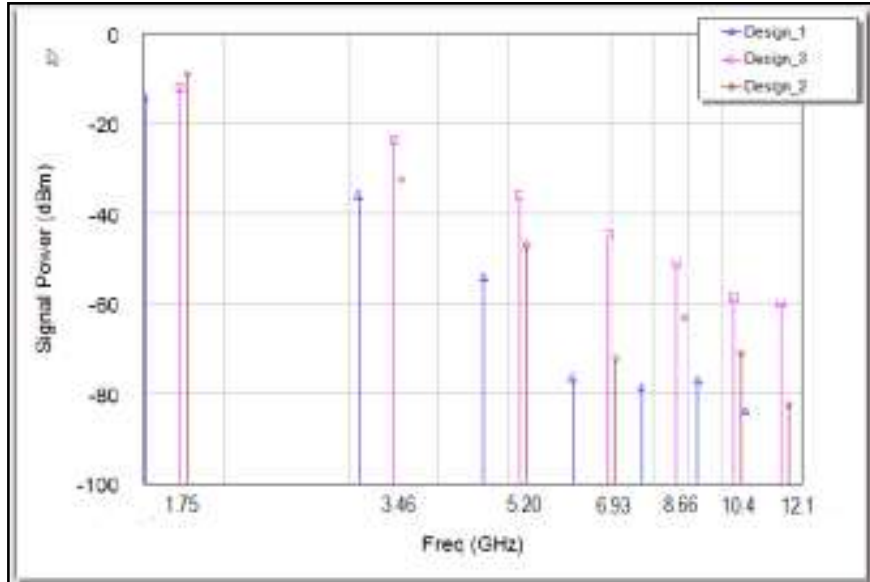

Figure 8: Power Spectrum for three differ rent topologies simulated with R3_S2

Spectrum signal for all the three topologies are shown in Figure 8. The spectrum for topology in Design_2 is $-9 \mathrm{dBm}$ at $1.78 \mathrm{GHz}$ resonance frequency. Design_1 topology resulted in lowest spectrum when integrated with R3_S2, which was $17 \mathrm{dBm}$ at $1.55 \mathrm{GHz}$ resonance frequency. Meanwhile, Design_3 topology resulted in $-14.5 \mathrm{dBm}$ spectrum signal at $1.75 \mathrm{GHz}$ resonance frequency.

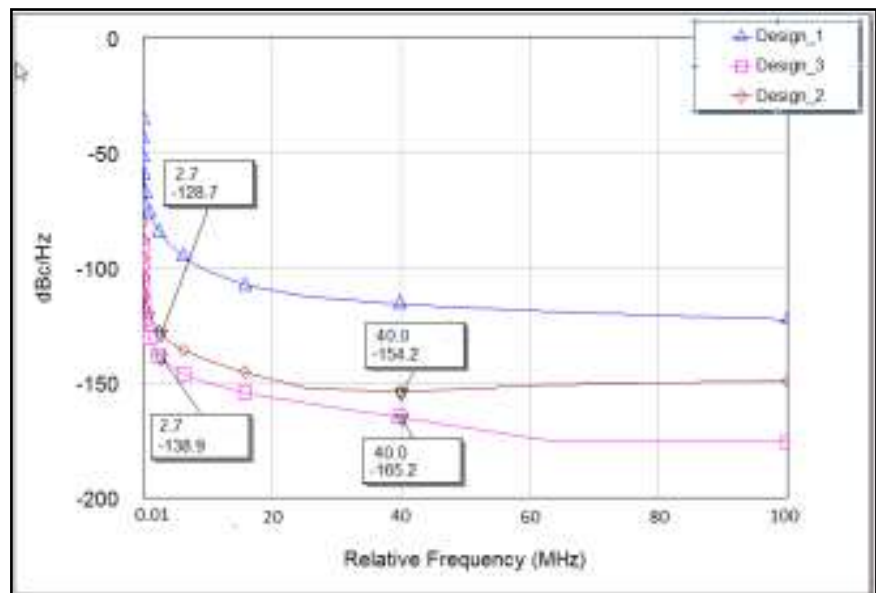

Figure 9: Phase Noise Performance for three different topologies simulated with R3_S2

Figure 9 shows the phase noise performance for three different Pierce oscillator circuit topologies. As shown in the figure, the simulated phase noise of the output signal from Design_1 topology was $-56.8 \mathrm{dBc} / \mathrm{Hz}$ at $100-\mathrm{kHz}$ offset frequency with a floor of $-120 \mathrm{dBc} / \mathrm{Hz}$. The phase noise of Design_2 and Design_3 were $-80.1 \mathrm{dBc} / \mathrm{Hz}$ and -90.3 at 10 $\mathrm{kHz}$ offset frequency respectively and the noise floor for Design_2 was $-150.4 \mathrm{dBc} / \mathrm{Hz}$ and for Design_3 at - 
$175.6 \mathrm{dBc} / \mathrm{Hz}$. The phase noise performance of Design_2 and Design_3 topology was better than design_1. Obviously, Design_3 has the best phase noise performance and the lowest noise floor when compared with the other two oscillators' topologies. The Leeson phase noise equation is expressed in equation 5 below.

$$
\mathcal{L}_{f_{m}}=10 \log \left[\frac{F k T}{P_{s i g}} \frac{1}{8 Q_{L}^{2}}\left(\frac{f_{o}}{f_{m}}\right)^{2}\right]
$$

Where $L_{f m}$ is the single side band Phase Noise, $P_{s i g}$ is the oscillator output power, $F$ is the active device noise factor, $k$ is the Boltzmann's constant, $T$ is the temperature, $f_{o}$ is the oscillator resonance frequency, $f_{m}$ is the offset frequency and $Q_{L}$ is the loaded $\mathrm{Q}$. Loaded $\mathrm{Q}$ exist when a resonator was connected to the sustaining circuit, their total losses were combined. Thus, although Design_2 has higher signal spectrum as compared to Design_3, extra CMOS in the sustaining circuit will overload the overall circuit and degraded the performance.

\section{CONCLUSION}

The simulation and the comparison of CMOS oscillators based on CMOS MEMS SAW resonator has been discussed in this paper. The oscillators have been simulated using three different Pierce oscillator circuit topologies. The result showed that topology from Design_3 has the best phase noise performance and settling time as compare to the other two topologies in Design_1 and Design_2. The settling time for Design_3 is 10ns and the phase noise performance was $90.3 \mathrm{dBc} / \mathrm{Hz}$ at $10-\mathrm{kHz}$ offset frequency. Design_2 required 40ns to achieve stability and the phase noise performance was $-80.1 \mathrm{dBc} / \mathrm{Hz}$ at $10-\mathrm{kHz}$ offset frequency. Meanwhile, Design_1 required 30ns before it can achieve stability and the phase noise performance was $-56.8 \mathrm{dBc} / \mathrm{Hz}$ at $100-\mathrm{kHz}$ offset frequency. Phase noise performance is the most important criteria for oscillator. In most cases, the resonator used in an oscillator must have high Q in order for the oscillator to have good phase noise performance. However, the sustaining amplifier circuit can also be used to improve the phase noise performance of the oscillator. Thus, the discussion of the future oscillator design for CMOS MEMS SAW resonator will be based on pierce topology in Design_3.

\section{REFERENCES}

[1] C. T. C. Nguyen, "Mechanical radio," Spectrum, IEEE, vol. 46, no. 12, pp. 30-35, 2009.

[2] S. D. Toso, A. Bevilacqua, A. Gerosa, and A. Neviani, "A thorough analysis of the tank quality factor in LC oscillators with switched capacitor banks," in IEEE International Symposium on Circuits and Systems (ISCAS 2010), 2010, no. 13, pp. 1903-1906.

[3] J. T. M. van Beek and R. Puers, "A review of MEMS oscillators for frequency reference and timing applications," J. Micromechanics Microengineering, vol. 22, no. 1, p. 013001, Jan. 2012.
[4] C. T. C. Nguyen, "RF MEMS in wireless architectures," in Design Automation Conference, 2005. Proceedings. 42nd, 2005, pp. 416-420.

[5] A. N. Nordin and M. E. Zaghloul, "Design, Implementation and Characterization of Temperature Compensated SAW Resonators in CMOS Technology for RF Oscillators ," The george Washington University, 2008.

[6] S. S. Rai and B. P. Otis, "A 600uW BAW-Tuned Quadrature VCO Using Source Degenerated Coupling," Solid-State Circuits, IEEE J., vol. 43, no. 1, pp. 300-305, 2008.

[7] Z. Chengjie, N. Sinha, J. Van der Spiegel, and G. Piazza, "Multifrequency Pierce Oscillators Based on Piezoelectric AlN ContourMode MEMS Technology," Microelectromechanical Syst. J., vol. 19, no. 3, pp. 570-580, 2010.

[8] Z. Chengjie, J. Van der Spiegel, and G. Piazza, "Dual-Mode Resonator and Switchless Reconfigurable Oscillator Based on Piezoelectric AlN MEMS Technology," Electron Devices, IEEE Trans., vol. 58, no. 10, pp. 3599-3603, 2011.

[9] J. Verd, A. Uranga, G. Abadal, J. L. Teva, F. Torres, J. L. Lopez, E. Perez-Murano, J. Esteve, and N. Barniol, "Monolithic CMOS MEMS Oscillator Circuit for Sensing in the Attogram Range," Electron Device Lett. IEEE, vol. 29, no. 2, pp. 146-148, 2008.

[10] M. L. Johnston, I. Kymissis, and K. L. Shepard, "FBAR-CMOS Oscillator Array for Mass-Sensing Applications," Sensors Journal, IEEE, vol. 10, no. 6, pp. 1042-1047, 2010.

[11] A. Tocchio, A. Caspani, G. Langfelder, A. Longoni, and E. Lasalandra, "A Pierce oscillator for MEMS resonant accelerometer with a novel low-power amplitude limiting technique," in Frequency Control Symposium (FCS), 2012 IEEE International, 2012, pp. 1-6.

[12] G. K. Ho, K. Sundaresan, S. Pourkamali, and F. Ayazi, "Micromechanical IBARs: Tunable High-Q Resonators for Temperature-Compensated Reference Oscillators," Microelectromechanical Syst. J., vol. 19, no. 3, pp. 503-515, 2010.

[13] S. Seth, S. Wang, T. Kenny, and B. Murmann, "A-131-dBc/Hz, 20-MHz MEMS oscillator with a 6.9-mW, 69-kohm, gain-tunable CMOS TIA," in ESSCIRC (ESSCIRC), 2012 Proceedings of the, 2012, pp. 249-252.

[14] F. Nabki, K. Allidina, F. Ahmad, P. V Cicek, and M. N. El-Gamal, "A Highly Integrated $1.8 \mathrm{GHz}$ Frequency Synthesizer Based on a MEMS Resonator," Solid-State Circuits, IEEE J., vol. 44, no. 8, pp. 2154-2168, 2009.

[15] H. M. Lavasani, W. Pan, B. Harrington, R. Abdolvand, and F. Ayazi, “A $76 \mathrm{~dB}$ Using Broadband Current Pre-Amplifier for High Frequency Lateral MEMS Oscillators," vol. 46, no. 1, pp. 224-235, 2011.

[16] H. M. Lavasani, P. Wanling, B. P. Harrington, R. Abdolvand, and F. Ayazi, "Electronic Temperature Compensation of Lateral Bulk Acoustic Resonator Reference Oscillators Using Enhanced Series Tuning Technique," Solid-State Circuits, IEEE J., vol. 47, no. 6, pp. 1381-1393, 2012.

[17] Z. Chengjie, J. Van Der Spiegel, and G. Piazza, "1.05-GHz CMOS oscillator based on lateral- field-excited piezoelectric AlN contourmode MEMS resonators," Ultrason. Ferroelectr. Freq. Control. IEEE Trans., vol. 57, no. 1, pp. 82-87, 2010.

[18] F. Nabki, K. Allidina, F. Ahmad, P. V Cicek, and M. N. El-Gamal, "A Highly Integrated $1.8 \mathrm{GHz}$ Frequency Synthesizer Based on a MEMS Resonator," Solid-State Circuits, IEEE J., vol. 44, no. 8, pp. 2154-2168, 2009.

[19] H. M. Lavasani, P. Wanling, B. Harrington, R. Abdolvand, and F. Ayazi, "A 76 dB, $1.7 \mathrm{GHz} 0.18$ um CMOS Tunable TIA Using Broadband Current Pre-Amplifier for High Frequency Lateral MEMS Oscillators," Solid-State Circuits, IEEE J., vol. 46, no. 1, pp. 224-235, 2011.

[20] N. M. Nguyen and R. G. Meyer, "Start-up and frequency stability in high-frequency oscillators," Solid-State Circuits, IEEE J., vol. 27, no. 5, pp. 810-820, 1992.

[21] R.Behzad, Design of Analog CMOS Integrated Circuits. McGraw Hill, 2001.

[22] B. Otis, "The design and implementation of an ultra low power RF oscillator using micromachined resonators," vol. Master Sci. Plan II Berkeley Dep. ..., p. 77, 2002. 